\title{
Experimental and Numerical Evaluation and Optimization of a Non Standard Pitot/Sampling Probe
}

\author{
Andrea Shmueli ${ }^{1}$, Tor Erling Unander ${ }^{2}$, Ole Jørgen Nydal ${ }^{1}$ \\ ${ }^{1}$ Norwegian University of Science and Technology, Department of Energy and Process Engineering, Trondheim, Norway \\ ${ }^{2}$ Department of Petroleum Research, SINTEF, Trondheim, Norway \\ Email: andrea.shmueli@ntnu.no
}

Received September 4, 2013; revised October 4, 2013; accepted October 11, 2013

Copyright (C) 2013 Andrea Shmueli et al. This is an open access article distributed under the Creative Commons Attribution License, which permits unrestricted use, distribution, and reproduction in any medium, provided the original work is properly cited.

\begin{abstract}
An isokinetic sampling probe is designed and constructed to measure entrained liquid droplet fluxes in separated gasliquid pipe flows. This probe also has the capability of working as a non-standard Pitot tube when the sampling is stopped. CFD simulations using the commercial software Ansys CFX were carried out for single phase gas flow to analyze the non-standard design. Pitot tube velocity calculations and isokinetic sampling conditions were studied. The predicted results were compared against theoretical velocity profiles from the literature and with gas single phase experimental data acquired in a horizontal $49 \mathrm{~m}$ long steel pipeline with an internal diameter of $69 \mathrm{~mm}$. The experiments were done by using a dense gas (SF6) at 7 bara. An asymmetry of the experimental velocity profiles reproduced with the numerical simulations. The CFD simulations made it possible to verify the design and predict and correct an installation problem.
\end{abstract}

Keywords: Isokinetic Probe; Pitot Tube; CFD; Flow; Installation Effects

\section{Introduction}

Pitot probes are devices which are commonly used in the industry to measure the local velocity in gases flowing in pipes or ducts. The dynamic pressure $\left(P_{d}=P_{t}-P_{s}\right)$ of the fluid stream is measured by the Pitot probe and the velocity can be calculated from it. When the gas compressibility effect can be neglected, the local velocity can be calculated from:

$$
U_{g}=C \cdot \sqrt{\frac{2 \cdot P_{d}}{\rho_{g}}}
$$

where $C$ is a calibration constant.

The Pitot tubes have been used for measuring the gas dynamic pressure in gas-liquid flows [1-4]. However, the calculation of the velocity from the pressure values is not straightforward and will depend upon the flow regime [5]. In gas flow with liquid droplet entrainment, it is a common practice to use isokinetic sampling probes to extract flow from the main stream in order to get the local dispersed droplet flux. These probes are designed to have a Pitot-like geometry and pressure tapings and can be designed to measure the local velocity when the sampling is stopped. The probes are generally not standard so their design must be tested and validated. Two aspects that should be taken into account when designing a new Pitot probe are the velocity measured by the Pitot probe in an ideal flow and the effect of the probe presence on the upstream flow [6]. Due to the complexity of multiphase flows, the probe design and installation are evaluated by using single phase gas conditions.

In this paper, a design and installation assessment of the non standard Pitot/sampling probe is done by the analysis of single phase gas experimental data and simulation of the probe current design using CFD tools.

\section{Probe Design}

The sampling/Pitot probe is designed to be able to sample a liquid flux. Some authors have demonstrated that the effect of the sampling tube diameter and length of the probe on the measured droplet flux is negligible $[7,8]$. However in this study the criteria used to select the probe diameter was associated with the maximum possible droplet size. Two correlations were used: one for gas/ liquid systems and another one for liquid/liquid systems. Kocamustafaogullari et al. (1994) [9] presented a correlation for the maximum droplet diameter in annular flows. 
The correlati on is a function of the fluid properties and of the local energy dissipated by the turbulence.

$$
\begin{array}{r}
\frac{d_{\max }}{d_{h}}=2.609 \cdot C_{w}^{-4 / 15} \cdot W e_{m}^{-3 / 5} \cdot\left(\frac{\mathrm{Re}_{g}^{4}}{\mathrm{Re}_{l}}\right)^{1 / 15} \cdot\left[\left(\frac{\rho_{g}}{\rho_{l}}\right) \cdot\left(\frac{\mu_{g}}{\mu_{l}}\right)\right]^{4 / 15} \\
C w= \begin{cases}0.028(N \mu)^{-4 / 5} & \text { for } N \mu \leq 1 / 15 \\
0.25 & \text { for } N \mu>1 / 15\end{cases}
\end{array}
$$

The viscosity number is defined by,

$$
N \mu=\frac{\mu_{f}}{\sqrt{\rho_{l} \cdot \sigma \cdot \sqrt{\frac{\sigma}{g} \cdot \Delta \rho}}}
$$

Kubie and Gardner (1997) [10] developed a correlation for maximum droplet size in liquid/liquid systems.

$$
\begin{array}{r}
\left(\frac{d_{\max } \cdot \rho_{c} \cdot \bar{U}^{2}}{\sigma}\right) \cdot\left(\frac{f \cdot d_{\max }}{D}\right)^{\frac{2}{3}}=0.369 \\
f=0.076 \cdot(\operatorname{Re})^{-0.25}
\end{array}
$$

The probe diameter should allow for measurements in oil-water-gas flow systems. The probe has a $4 \mathrm{~mm}$ inner diameter, a $0.2 \mathrm{~mm}$ wall thickness. It is possible to measure within $4.2 \mathrm{~mm}$ of the pipe wall. To avoid disturbing the flow, the opening of the sampling probe extends $50 \mathrm{~mm}$ upstream $\left(\approx 11.4 d_{p}\right)$. The dynamic pressure is read at $3.75 d_{p}$ and the static pressure sensed at the pipe wall on the probe stem plane. Two hoses were connected to transmit the dynamic pressure from the holes to the differential pressure transducer. The probe can traverse the vertical pipe diameter using a linear actuator and has the ability to work as a sampling and Pitot probe when a manual ball valve connected to the sampling line is closed. The non standard Pitot probe used in this study is schematically shown in Figure 1.

\section{Experiments}

\subsection{Experimental Setup}

The experiments were carried out in the medium-scale flow loop at SINTEF Multiphase Flow laboratory in Trondheim, Norway. The facility consists of a horizontal $69 \mathrm{~mm}$ inner diameter, $50 \mathrm{~m}$ long pipeline. The probe test section is located about 580D downstream the mixing point.

\subsection{Experimental Measurements}

Pitot measurements on the vertical diameter were carried out using single gas phase SF6 (Sulphur hexafluoride) at 7 bara and $20^{\circ} \mathrm{C}$. Three experimental gas velocities were tested 4,6 and $8 \mathrm{~m} / \mathrm{s}$. The measured gas density and dynamic viscosity from the experiments are $\rho_{g}=41.91$ $\mathrm{Kg} / \mathrm{m}^{3}$ and $\mu_{g}=1.5 \mathrm{e}-05 \mathrm{~Pa} \cdot \mathrm{s}$ respectively.

The measurements are compared against two theoretical velocity profiles. Following [11] the velocity distribution in the main body of flow can be written as shown in Equation (2), where $\alpha$ is a power law constant that in this case is 0.111 as is proposed by [12].

$$
\frac{U_{g}(y)}{U_{\max }}=(\xi)^{\alpha}
$$

where $\xi=y / R$ is the normalized distance from the wall to the pipe center. The second profile is obtained by following the modified log-wake model [13] for turbulent pipe flow:

$$
\begin{aligned}
\frac{U_{\max }-U}{U^{*}}= & -\frac{\sqrt{3} e}{2} \ln \xi+\left(2-\frac{\sqrt{3} e}{6}\right) \\
& -6 \xi^{2}+\left(4+\frac{\sqrt{3} e}{6}\right) \xi^{3}
\end{aligned}
$$
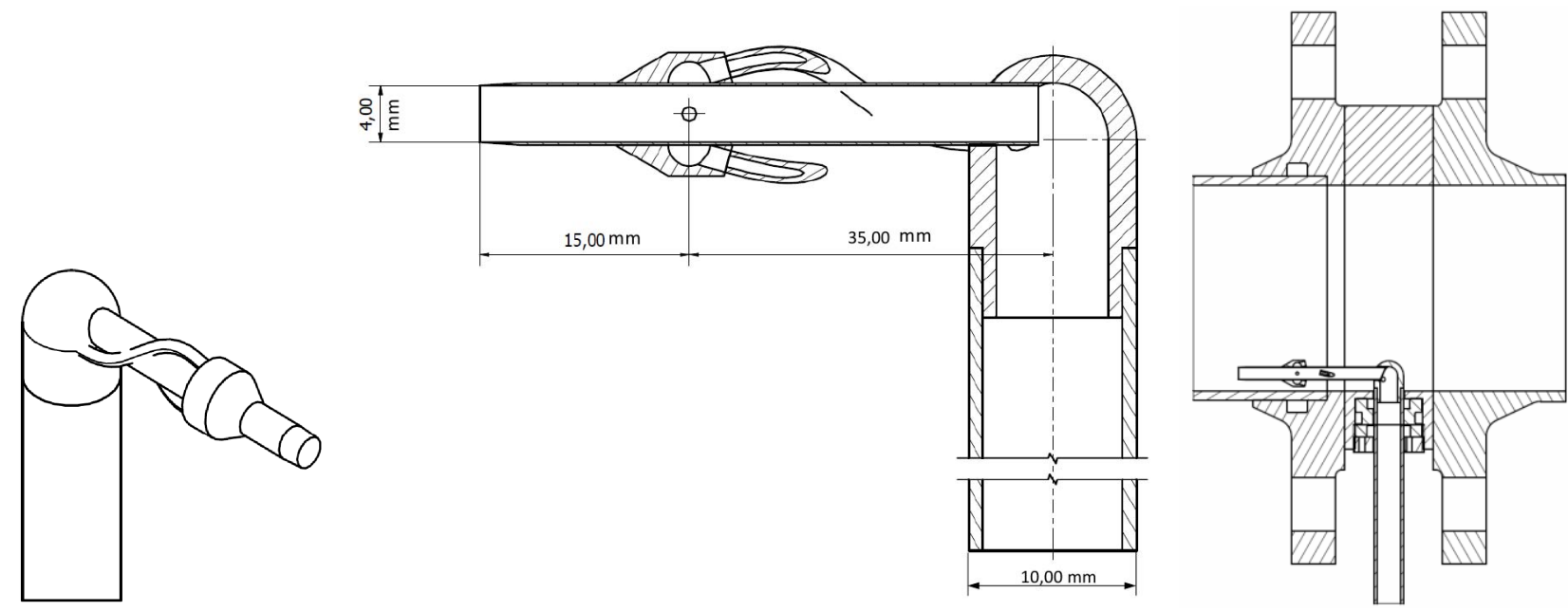

Figure 1. Pitot probe geometry. 
The local gas velocity measurements and the theoretical profiles are normalized by their maximum value and shown in Figure 2. The experimental velocity profiles for all the tests are not symmetric and a systematic error is shown for all of them on the upper half section of the pipe. However, there is a good fitting between the experimental velocity profile and the theoretical one on the bottom part on the pipe.

\section{CFD Model Details}

3D CFD simulations of the flow around a non standard Pitot probe were developed using the commercial software ANSYS-CFX ${ }^{\odot}$ (V-13) which employs the finite volume method for solving the conservation equations.

\subsection{Cases under Study}

The simulations were carried out using single gas phase SF6 (Sulphur hexafluoride) at 7 bara, $20^{\circ} \mathrm{C}$ and $4 \mathrm{~m} / \mathrm{s}$. The calculated Mach number for the tested conditions is lower than 0.3 and thereby the fluid is considered as incompressible on the simulations [14]. The goal of the model is to simulate the flow around the designed non standard Pitot probe in order to find the origin of the experimental velocity profile asymmetry, predicting a possible installation effect on the gas velocity calculation and afterwards improving the current design. Two locations of the Pitot probe above the pipe center were numerically studied (See Table 1).

\subsection{CFD Model General Settings}

The turbulence model was a homogeneous $\mathrm{K}-\varepsilon$ model. All the simulations were considered as steady state con-

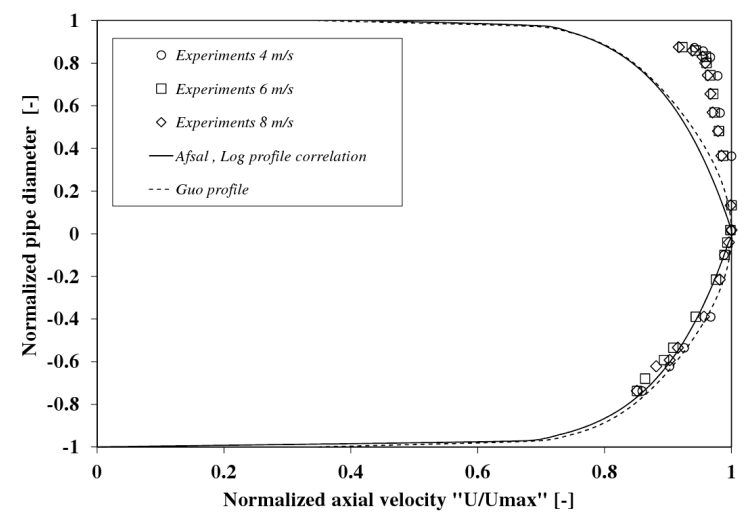

Figure 2. Experimental and theoretical normalized gas velocity profiles for 4,6 and $8 \mathrm{~m} / \mathrm{s}$.

Table 1. Simulated cases.

\begin{tabular}{lc}
\hline Case Location of the probe opening from the bottom of the pipe $[\mathrm{mm}]$ \\
\hline 1 & 51 \\
2 & 59
\end{tabular}

ditions. For all the simulations, the convergence was reached when the maximum and RMS residual error for any parameter was reduced to less than $4 \mathrm{e}-04$ and $4.2 \mathrm{e}-05$ respectively.

\subsection{Boundary Conditions and Simulation Domain}

The simulated domain consists of the probe and a section of the pipe (3.8 m upstream of the probe and $314 \mathrm{~mm}$ downstream of it). The hoses used for the total pressure sensing were not included on the model. The imposed boundary conditions were total pressure at the inlet (Upstream Boundary) and uniform mass flow at the outlet boundary condition (Downstream Boundary). All the walls were treated as no-slip walls.

\subsection{Mesh}

The fluid domain was meshed using the commercial Workbench $\mathrm{CFX}^{\odot}$ Mesh Module. The created meshes were non-structured formed by tetrahedral, wedge and pyramid elements. A grid dependence procedure was carried out in order to select the right mesh (see Table 2).

Four parameters were compared in order to select the right mesh for the simulations: The pressure loss on the pipe segment, maximum $\mathrm{Y}+$ value, the gas velocity on the probe opening calculated from Equation (1) using the static pressure value at the current location Ps-1 (See Figure 3 and 4 ).

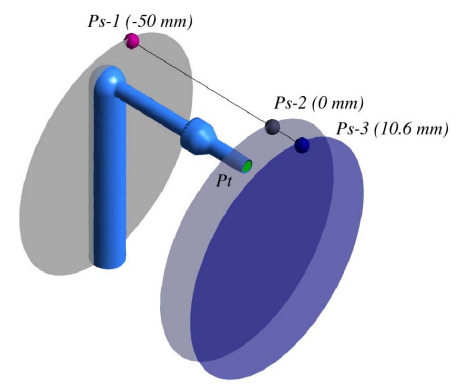

Figure 3. Location of the specific calculated parameters in the domain.

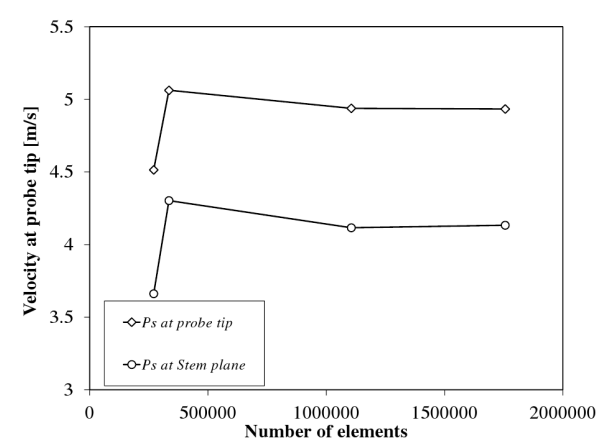

Figure 4. Mesh dependency study. Variable: velocity at Pitot opening. 
The velocity profile on a line is located on the probe opening Ps-2, (See Figure 5). A percent error lower than $3 \%$ between each mesh and the finest one of every physical variable compared was used as selection criteria. There are some qualitative differences between all the meshes especially close to the probe tip. The biggest difference between Mesh 1 and Mesh 4 is 7\%. The selected mesh for the simulations was Mesh 3.

\section{Results}

\subsection{Pitot Geometry Effect}

One possible cause of the asymmetry in velocity profiles around the pipe centerline is a blockage effect of the stem in the flow upstream the probe tip. For this reason, the vertical velocity profiles in different locations downstream and upstream the probe tip are plotted in Figures 6 and 7. The profiles from the pipeline inlet to the probe location are compared (Figure 6) showing symmetry with respect to the pipe axis. The flow in the pipe is developed before 20D. There are no upstream disturbances on the profiles due to the presence of the Pitot. However, the probe stem has a blockage effect on the profiles downstream the tip of the probe, mainly due to the reduction of the flow area (Figure 7). This behavior

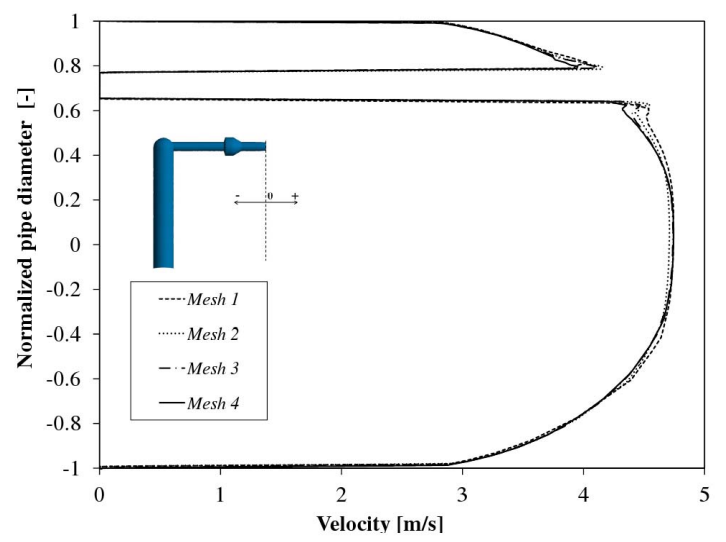

Figure 5. Mesh dependency study variable: velocity profile on a line located at the probe opening.

Table 2. Generated meshes for case 1.

\begin{tabular}{ccccc}
\hline Mesh & 1 & 2 & 3 & 4 \\
\hline Max Y+ & 13.27 & 13.52 & 13.56 & 13.55 \\
$\begin{array}{c}\text { Connectivity } \\
\text { number }\end{array}$ & $3-46$ & $3-46$ & $2-44$ & $2-50$ \\
Element vol ratio & $1-52$ & $1-48$ & $1-93$ & $1-82$ \\
Min face angle & $18-84$ & $17-86$ & $16-86$ & $12-87$ \\
Max face angle & $65-130$ & $66-136$ & $66-131$ & $64-134$ \\
Edge length ratio & $1-43$ & $1-43$ & $1-16$ & $1-16$ \\
Elements & 270,328 & 334,852 & $1,105,596$ & $1,756,149$ \\
Nodes & 92,570 & 111,118 & 383,564 & 600,838 \\
\hline
\end{tabular}

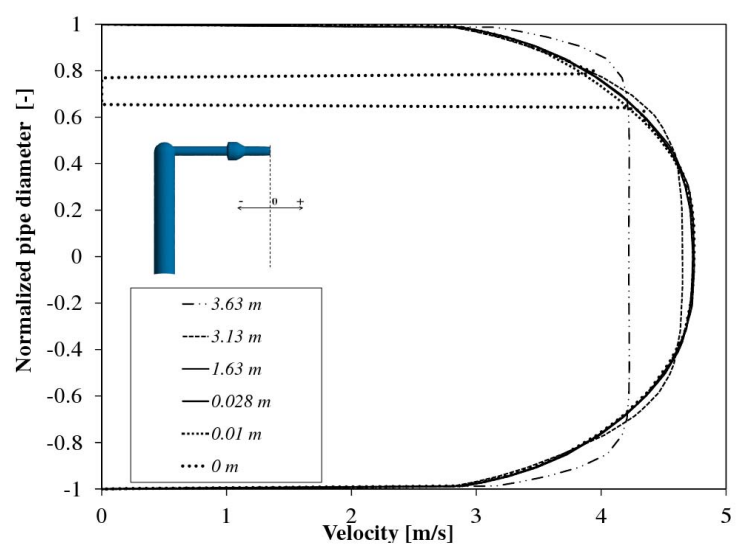

Figure 6. Velocity profiles from the pipe inlet. Case 1.

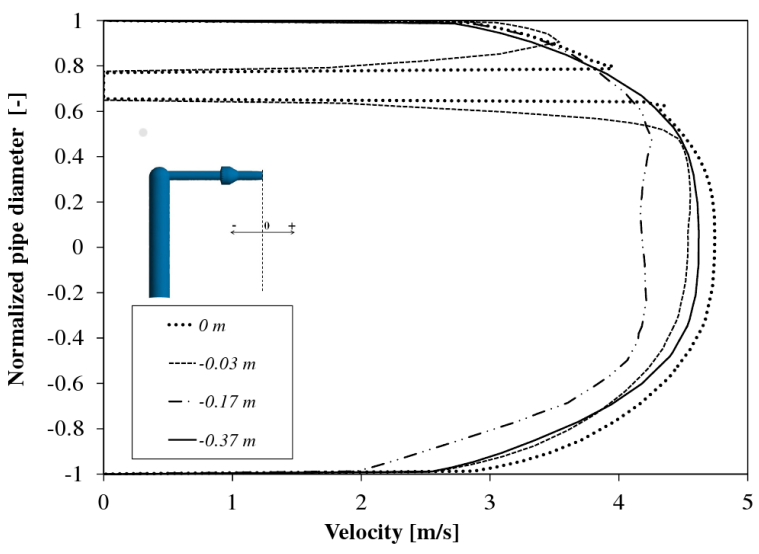

Figure 7. Velocity profiles downstream the probe tip. Case 1.

was expected as the ratio of the Pitot tube diameter to the pipe diameter does exceed 0.02 [14].

\subsection{Pitot Vertical Location}

Two cases were studied as presented in Table 1. The vertical location of the probe has a qualitative and quantitative effect on the static pressure distribution around the Pitot. The closer the Pitot is to the upper side of the pipe the lower is the pressure on the probe plane (See Figure 8). Near the top of the pipe the probe disturbs the flow and accelerates it creating a low pressure area on the top of the probe caused by the area reduction between the stem of the probe and the pipe.

The velocity at the probe opening (Table 3) is calculated using Equation (1) with the total pressure value at the probe tip and the static pressure values at Ps- 1 , Ps. 2 and Ps-3 (See Figure 3). The percentage errors in the velocity calculation using Ps-1 or Ps-2 are $10 \%$ and 17 for Cases 1 and 2 respectively. The percentage errors when sensing the static pressure in front the Pitot tip (Ps-3) are $0.5 \%$ and $0.7 \%$ for Cases 1 and 2 respectively.

A comparison of the calculated velocity values and the 


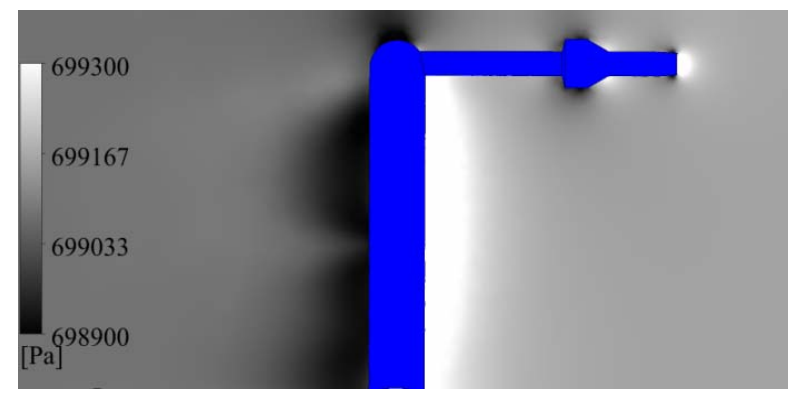

Figure 8. Static pressure contour case 2.

Table 3. Velocity at the probe opening calculated with total pressure and static pressure at point 1 and 2 .

\begin{tabular}{ccccc}
\hline Case & Location & $\begin{array}{c}\text { Static Pressure } \\
{[\mathrm{Pa}]}\end{array}$ & $\begin{array}{c}\text { Total Pressure } \\
{[\mathrm{Pa}]}\end{array}$ & $\begin{array}{c}\text { Velocity at the } \\
\text { probe opening } \\
{[\mathrm{m} / \mathrm{s}]}\end{array}$ \\
\hline & Ps-1 & 699,344 & - & 4.92 \\
1 & Ps-2 & 699,428 & - & 4.49 \\
& Ps-3 & 699,434 & & 4.46 \\
& Pt & & 699,851 & \\
& Ps-1 & 699,003 & - & 4.89 \\
& Ps-2 & 699,151 & - & 4.10 \\
& & & & 4.08 \\
& Ps-3 & 699,156 & & - \\
\hline
\end{tabular}

experimental one is made in Figure 9. Using the static pressure at the probe tip plane to calculate the local velocity shows a better fit with the theoretical profiles.

\subsection{Pitot Probe Sampling under an Isokinetic Condition}

The main goal of this simulation was to obtain the pressure loss inside the probe working under isokinetic condition. It is important to establish the pressure loss between the probe tip and the dynamic pressure ports inside it. For this simulation just Case 2 was analyzed.

The simulation and mesh selection was done following the steps explained on section 4. The flow conditions and fluid are the same as in the previous simulations. The imposed boundary conditions were total pressure at the inlet (Upstream Boundary), uniform mass flow at the outlet of the probe (calculated from the isokinetic condition) and uniform mass flow at the outlet boundary condition (Downstream Boundary). All the walls were treated as no-slip walls. The k- $\varepsilon$ turbulence model was used on the simulations.

The streamlines approaching the probe opening and inside it are plotted in Figure 10. All the streamlines are undisturbed as the probe is not present and the velocity of the flow entering the probe is the same as in the main body of the flow so the conditions for isokinetic sampling are accomplished.

The total pressure is averaged on planes perpendicular to the flow inside the probe (See Figure 11). The total pressure holes are currently located on the position marked by the dotted line. The pressure loss between the probe opening and the total pressure holes is $33 \mathrm{~Pa}$.

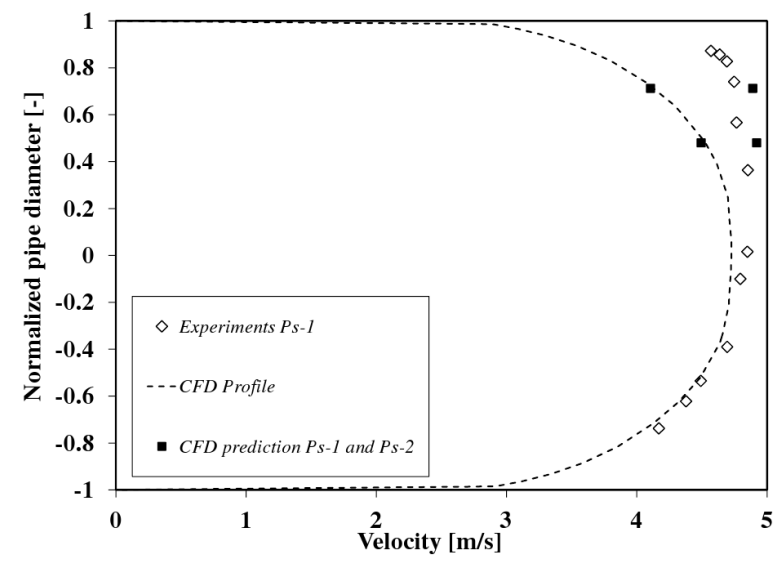

Figure 9. Comparison between experimental, theoretical and CFD normalized gas velocity profile at $4 \mathrm{~m} / \mathrm{s}$.

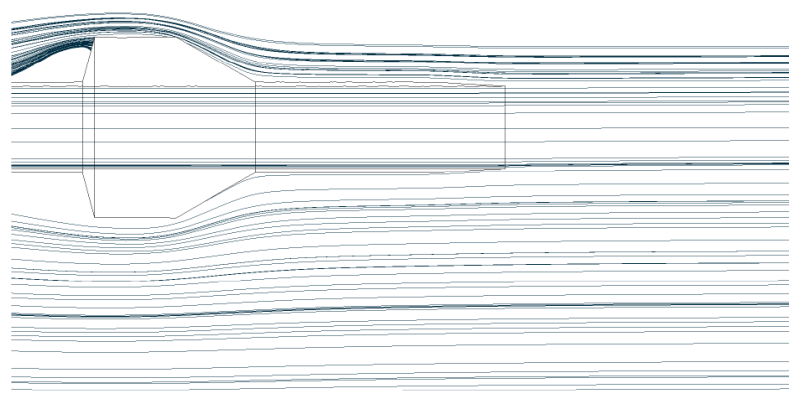

Figure 10. Streamlines entering the probe.

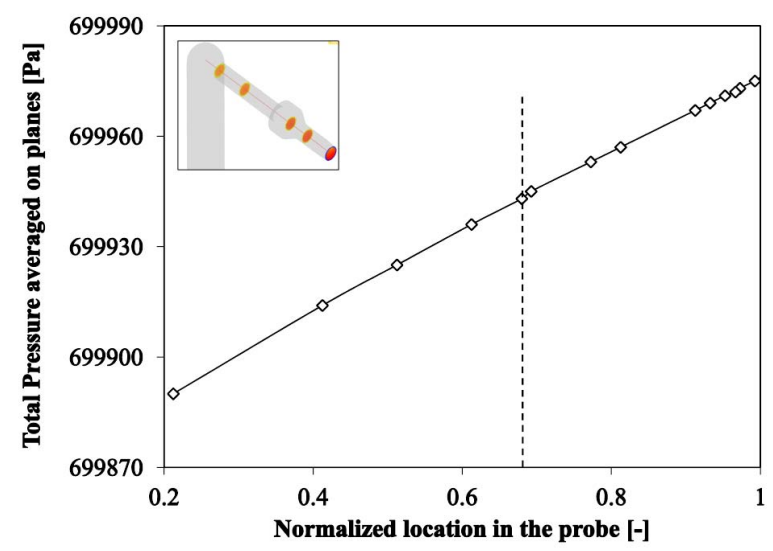

Figure 11. Total pressure averaged on planes inside the probe where location 1 is the probe opening. 


\section{Experiments on the Upgraded Installation}

New experiments at $4 \mathrm{~m} / \mathrm{s}$ were developed using an upgraded setup in which the static pressure tap was located on the same plane of the probe tip. The velocity profiles are symmetric in accordance to the pipe axial direction. The experiments are compared against the CFD profile showing an agreement and improvement in comparison with the previous setup (See Figure 12).

\section{Conclusions and Remarks}

A non-standard Pitot/sampling probe was experimentally tested and simulated using Ansys CFX (V13) to validate its accuracy and to determine any design or installation problem. The current experimental setup caused asymmetries on the measured gas velocity profiles.

The experiments were conducted for 3 velocities while the numerical simulations were carried out for one velocity. The obtained experimental asymmetries show a systematic behavior so the numerical results are extrapolated to other flow conditions.

The CFD simulations were concentrated on two probe vertical locations where the velocity profiles present the asymmetry. The effect of the probe location on the vertical pipe diameter, static pressure port location on the pipe wall, probe stem location and dynamic pressure ports location was studied. The location of the static pressure tap at either the probe tip plane or upstream of it will give more real and accurate velocity values.

As a result from the simulations, the static pressure tap at the top of the pipe was relocated in order to have a real and accurate reading of the static pressure. The probe itself generates disturbances of the flow downstream of it but not upstream of it.

A simulation of the isokinetic sampling probe was carried out to obtain the pressure drop inside the probe. It

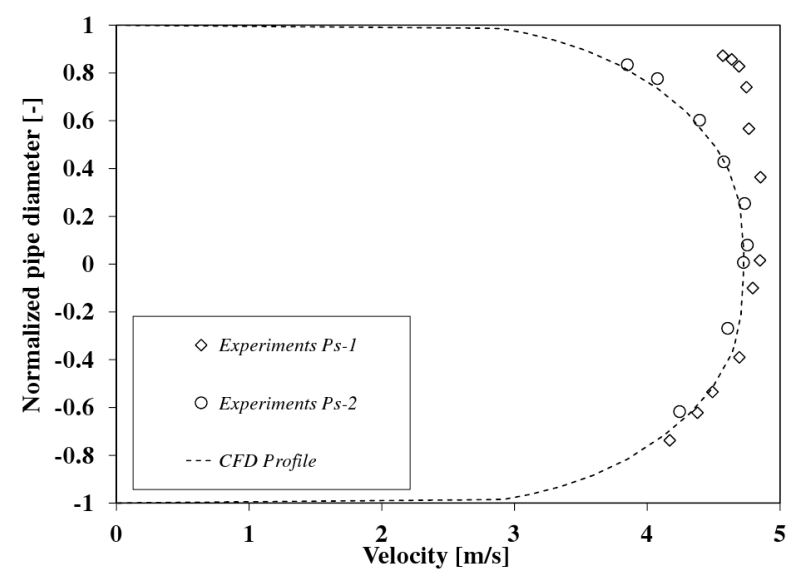

Figure 12. Comparison of the experiments carried out the upgraded facility at $4 \mathrm{~m} / \mathrm{s}$ with previous experiments and CFD profile. was recommended for further probe designs to place the dynamic pressure holes on the probe closer to the probe tip in order to avoid the pressure losses and have a better reading of the pressure.

Experiments with a new configuration with the static pressure tap on the same plane as the probe tip were carried out at $4 \mathrm{~m} / \mathrm{s}$ showing an improvement on the measurements with symmetric velocity profiles which agreed with the theoretical predictions.

\section{Acknowledgements}

The financial and research support from Total E\&P and Sintef Petroleum Research are greatly appreciated.

\section{REFERENCES}

[1] L. A. Dykhno, "Maps of Mean Gas Velocity for Stratified Flows with and without Atomization," International Journal of Multiphase Flow, Vol. 20, No. 4, 1994, pp 691-702.

http://dx.doi.org/10.1016/0301-9322(94)90039-6

[2] F. M. White, "Fluid Mechanics," 4th Edition, McGrawHill, New York, 1999.

[3] D. Tayebi, S. Nuland and P. Fuchs, "Droplet Transport in Oil/Gas and Water/Gas at High Densities," International Journal of Multiphase Flow, Vol. 26. 2000, pp. 741-761. http://dx.doi.org/10.1016/0301-9322(94)90039-6

[4] R. Skartlien, S. Nuland and J. Amundsen, "Simultaneous Entrainment of Oil and Water Droplets in High Reynolds Number Gas Turbulence in Horizontal Pipe Flow," International Journal of Multiphase Flow, Vol. 37 2011, pp. 1282-1293. http://dx.doi.org/10.1016/j.ijmultiphaseflow.2011.07.006

[5] G. Falcone, F. Hewitt and C. Alimonti, "Multiphase Flow Metering: Principles and Applications," Elsevier, Amsterdam, 2009.

[6] R. C. Baker, "Flow Measurement Handbook: Industrial Designs, Operating Principles, Performance and Applications," Cambridge University Press, New York, 2000. http://dx.doi.org/10.1017/CBO9780511471100

[7] M. Wicks and A. E. Dukler, "Entrainment and Pressure Drop in Concurrent Gas-Liquid Flow: Air-Water in Horizontal Flow," American Institute of Chemical Engineers, Vol. 6, No. 10, 1960, pp. 463-468. http://dx.doi.org/10.1002/aic.690060324

[8] L. Williams, "Effect of Pipe Diameter on Horizontal Annular Two-Phase Flow," PhD Thesis, University of Illinois at Urbana-Champaign, 1990.

[9] G. Kocamustafaogullari, S. R. Smits and J. Razi, "Maximum and Mean Droplet Sizes in Annular Two-Phase Flow," International Journal of Heat and Mass Transfer, Vol. 37, No. 6, 1994, pp. 955-965. http://dx.doi.org/10.1016/0017-9310(94)90220-8

[10] J. Kubie and G. C. Gardner, "Drop Sizes and Drop Dispersion in Straight Horizontal Tubes and Helical Coils," Chemical Engineering Science, Vol. 32, No. 2, 1977, pp. 195-202. 
http://dx.doi.org/10.1016/0009-2509(77)80105-X

[11] N. Afzal, A. Seena and A. Bushra, "Power Law Velocity Profile in Fully Developed Turbulent Pipe and Channel Flows," Journal of Hydraulic Engineering, Vol. 133, No. 9, 2007, pp. 1080-1086. http://dx.doi.org/10.1061/(ASCE)0733-9429(2007)133:9( $\underline{1080)}$

[12] W. J. Duncan, A. B. Thorn and A. D. Young, "Mechanics of Fluids," ELBS Edward Arnold, 1967.
[13] J. Guo and P. Juliem, "Modified Log-Wake Law for Turbulent Flow in Smooth Pipes," Journal of Hydraulic Research, Vol. 41, No. 4, 2003, pp. 493-501. http://dx.doi.org/10.1080/00221680309499994

[14] ISO, "Measurement of Fluid Flow in Closed ConduitsVelocity Area Method Using Pitot Static Tubes," ISO 3966, 1977, pp. 146-183. 


\section{Appendix}

\begin{tabular}{|c|c|}
\hline & Nomenclature \\
\hline$\rho$ & Density \\
\hline$P$ & Pressure \\
\hline$d$ & Diameter \\
\hline$D$ & Pipe diameter \\
\hline$C$ & Pitot calibration constant $\approx 1$ \\
\hline$U$ & Velocity \\
\hline$R$ & Pipe radius \\
\hline$U_{\max }$ & Velocity at the pipe center \\
\hline$d_{\max }$ & Maximum droplet size \\
\hline$d_{h}$ & Hydraulic diameter \\
\hline$d_{p}$ & Pitot diameter \\
\hline$C_{w}$ & Coefficient in Kocamustafaogullari correlation \\
\hline$y$ & Distance from the wall \\
\hline$\xi$ & Normalized distance from the wall to the pipe center \\
\hline$\mu$ & Dynamic viscosity \\
\hline$\alpha$ & Power law constant \\
\hline $\operatorname{Re}$ & Reynolds number \\
\hline$f$ & Friction factor \\
\hline$W e_{m}$ & Modified Weber number \\
\hline$N \mu$ & Viscosity number \\
\hline$\sigma$ & Surface tension \\
\hline$g$ & Gravity \\
\hline Subscrip & \\
\hline$c$ & Core \\
\hline$d$ & Dynamic \\
\hline$s$ & Static \\
\hline$t$ & Total \\
\hline$g$ & Gas \\
\hline$l$ & Liquid \\
\hline$p$ & Probe \\
\hline
\end{tabular}

